\title{
Traditional Fishing Knowledge Followed in Kombuthurai along Gulf of Mannar; A New Approaches on Hand Jigging of Cuttlefishes Using Biodegradable FAD
}

\author{
P. Chellamanimegalai ${ }^{1 *}$, S.J. Abisha Juliet Mary ${ }^{1}$, S. Manickavasagam ${ }^{1}$, \\ G. Kantharajan ${ }^{1}$, M. Dhayanath ${ }^{1}$ and B. Sundaramoorthy ${ }^{2}$
}

${ }^{1}$ ICAR - Central Institute of Fisheries Education, Panch Marg, Off Yari Road, Versova, Andheri West, Mumbai, India

${ }^{2}$ Dr.M.G.R Fisheries College and Research Institute, Thalainayeru, Nagapattinam, India

*Corresponding author

\section{A B S T R A C T}

\section{Keywords}

Traditional knowledge, Biodegradable materials, Fish aggregating devices, Baitfish, Hand jigging, Catching rate

Article Info

Accepted:

15 June 2019

Available Online:

10 July 2019
The present study was conducted to gather information on traditional knowledge is being followed by Kombuthurai fishers. Kombuthurai is a small fishing village located in Thoothukudi district where they are following a unique fishing practice by hook and line method, without employing any fishing nets. Major and minor targeted catches and its peculiar fishing ground, determined hook size and bait fish usage for those fishery were documented based on their traditional knowledge. Likewise, the comparison study on the hand jigging operation of cuttle fishes with and without using Fish Aggregating Devices was carried out for the short term period in Kombuthurai. FAD is made up of purely biodegradable materials consists of floating, attracting and anchoring section that installed at small scale level for exploiting cuttle fishes. It has been fixed in the fishing ground the day before fishing and the location noted down with the help of GPS. The fishing season is June to September. The maximum catch reported was $860 \mathrm{~kg} / \mathrm{boat} / \mathrm{day}$ during July month by FAD-associated hand jigging. It enhanced the maximization of net profit to fishers, increased fishing efficiency and the catching rate of cuttlefishes almost 3-4 times.

\section{Introduction}

Marine fisheries have a significant role in the Indian economy and well-being of communities, as well it also provided food security, job opportunities, Income, livelihoods and traditional cultural identity to the country. The present marine fish production is 3.83 million tonnes in 2017 , which has been increased with $5.6 \%$ from the last year 2016 and recorded as the second highest production after 2012 (CMFRI 2017- 
18). Likewise, Indian fisheries are contributed $0.91 \%$ to the total GDP of the country and $5.23 \%$ to the Agricultural GVA of the country (NFDB, 2019). The marine fish production of Gujarat and Tamil Nadu are 7.86 lakh tonnes and 6.55 lakh tonnes respectively, which was the first and second highest (CMFRI 201718). The prominent reason for this increasing trend of Indian marine capture fisheries is notable due to the active participation of fishermen. The exploitation of various fish stocks by using intensive fishing gears raises marine production.

At the same time, increasing production has diminished the catch per unit effort in the certain fishing ground. There are several reasons for diminishing marine fish production world over in terms of CPUE (Pauly et al., 2002). Among that, the employment of inappropriate gears and crafts has been considered as the prominent reason for overfishing (Kurien, 1989). Moreover, the damaging of the ecosystem being happened in most of the fishing ground due to an unsuitable gears to the ecosystem that makes the recovering of sustainability of resources as the most challengeable thing. Therefore, Fishers are focusing only to earn more profit without concerning about ecosystem sustainability is considered as one of the reasons for declining of CPUE (Fernando et al., 2017). Thoothukudi is one of the significant coastal district, consisting of 24 fishing villages where fishing is the primary livelihood option with an intensive fishing method (Handbook Thoothukudi, 2012). Still, there are some fishing villages focusing on the exploitation of targeted species in a sustainable manner that helps to retain our fishery resources in future.

Kombuthurai is the only village exclusively concentrated on the hook and line method as unique, sustainable fishing practices in the Gulf of Mannar. It is the cost effective fishing practices that never affected the aquatic environment, reduces the time of searching for fishes, reduction of bait fish expenses and minimizes the fuel cost. There are 150 fishermen families actively engaged in fishing practices, owning about 110 FRP vessels with the outboard engine of $9.9 \mathrm{HP}$ in Kombuthurai village. They belong to Mukkuva, a Latin Catholic fishing community people who migrated from the fishing village Kadiyapattinam, 35 years ago.

All the traditional fishing knowledge followed by those fishers has been initiated from their ancestors. The fishing practices accompanied in Kombuthurai were found to be the most sustainable and causes zero damage to the ecosystem. At present, Traditional knowledge and sustainable fishing practices followed by those fishermen were studied. The comparison study on cuttlefish fishery with and without fish aggregating devices also carried out during this present study.

\section{Materials and Methods}

Kombuthurai is a fishing village located in Coramendal coast of Thoothukudi district in Tamil Nadu (Figure 1). The survey was carried out among the fishermen from Kombuthurai to study the traditional knowledge and FAD-associated cuttlefish fishery.

The data collection was entirely based on an informal interview schedule with an effectual discussion. A total of 20 fishermen were involved in the interaction.

All the information was noted down simultaneously. Snow ball techniques were proceeded to gather the details about both traditional fishing practices and FADassociated cuttlefish fishery. The biased results on traditional methods were excluded by the method called triangulation. 


\section{Results and Discussion}

\section{Traditional knowledge behind the fishers}

Why Hook and line fishing methods are being followed in Kombuthurai?

In the Kombuthurai village, three types of line fishing such as traditional hand lining, long lining and traditional troll line methods are being practiced. However, the hand lining method and the trolling line are considered as best practices of this village. Baits either natural baits or colorful artificial baits were used to increase the catching efficiency of targeted fish groups. Long lining is the most sustainable and responsible fishing gear with compared to other fishing gears like trawling and gillnetting due to their size and species selection, absence of ghost fishing, survival after the escape, superior fish quality, less energy consumption and small damage to the ecosystem. So, Kombuthurai fishers were concentrated entirely on hook and line based fishing operation without the contribution of other fishing gears.

\section{Baits and its types}

Bait is the primary key factor for line fishing operation based on their feeding habits. Kombuthurai fishermen are using two types of baits, live baits as well as artificial baits. Live baits are locally known as "Thoota". They are using specific thoota for particular fishery (given in Table 1). Fishermen from other fishing villages are engaged in gill net operation to catch bait fishes. Kombuthurai fishers were expressed their individuality by using hook and line methods to catch live baits (given in Figure 2). Before the beginning of the fishing operation, the manufactured attractive lights have been used for catching bait fishes and immediately they are keeping it in the bait hold available on the deck with water.
There were different types of artificial hooks used which are available at nearby shops in Kombuthurai village. Hooks are classified according to their numbers indicating their size and strength. The size and strength of hooks increase proportionately.

The strongest hook (Hook no. 4) is used for tuna fishery. The size of the hooks and its corresponding fishery are given in Table 2.

\section{Fishing methods and targeted fishes}

The fishermen from Kombuthurai village usually go for single day fishing started in early morning at $3.00 \mathrm{am}$, and they have returned at $7.00 \mathrm{pm}$. FRP vessel with the outboard engine of $9.9 \mathrm{Hp}$ is used for fishing such as hand lining, long lining and troll lining.

The fishermen have focused mainly to capture large sized fishes to increase marketing efficiency. Dominant targeted fishes are Tuna, Seerfishes, Carangids and Cuttlefishes (Figure $3 \mathrm{~A}$ to 3D). The minor fish catches are from Grouper, Snapper, Goatfishes, and Pomfrets group.

The intensive catching of those targeted species varies with different fishing seasons and fishing grounds, which has been identified based on their traditional knowledge. The fishing grounds are defined with regards to the distance (in Nautical miles) from the shore. Different fishing seasons and fishing ground for targeted species are given in Table 3.

\section{Innovative FAD approaches in cuttlefish fishery}

The Fish aggregating devices employed in cuttlefish fishery of Kombuthurai is locally known as "Akkadi". It is an ecofriendly and economic approach used for attraction and retention of cuttlefishes at pelagic water. 
Table.1 List of live baits and its targeted fishery

\begin{tabular}{|l|l|}
\hline Live Baits (Thoota) & Targeted fishery \\
\hline Balistids (Klathimeen) & Carangids \\
\hline Indian Mackerel (Koluvalai), Loaches (Ayilai) & Seer fishes and Carangids \\
\hline Lesser sardines (Keerimeensalai) & Seer fishes and Yellow fin tuna \\
\hline
\end{tabular}

Table.2 Hook size and its fishery

\begin{tabular}{|l|l|}
\hline Hook size & Fishery \\
\hline Hook no. 6 & Carangids \\
\hline Hook no. 7 & Seer fishes \\
\hline Hook no. 4 & Tuna \\
\hline
\end{tabular}

Table.3 Different fishing seasons and fishing ground for targeted species

\begin{tabular}{|l|l|l|}
\hline Fishery & Fishing seasons & Fishing grounds \\
\hline Carangids & February to April & $\begin{array}{l}\mathrm{A}=39 \text { Nautical mile (Nm) par, B = 43 Nm par, C = 5th par and } \\
\mathrm{D}=35 \mathrm{Nm} \text { par }\end{array}$ \\
\hline tuna and seer fishes & May to August & $\begin{array}{l}\mathrm{A}=\mathrm{Seela} \text { par, B = Valayappu par, C = Vathai par, D = Oola par } \\
\text { and E= Osathi par }\end{array}$ \\
\hline $\begin{array}{l}\text { seer fish, carangids } \\
\text { and cuttle fishes }\end{array}$ & September to October & $\begin{array}{l}\mathrm{A}=\text { Osathi, B= Karuval, C= Periyathoppu, D= Kandeduthan par } \\
\text { and E= Keelipar }\end{array}$ \\
\hline Seer fishes & November to January & $\begin{array}{l}\mathrm{A}=\text { Klathi par 1, B= Punnakayalmadai, C= Semmenthalai par, } \\
\text { D= Manapadumannu par, E= Klathi par 2 and F=14 pagam par }\end{array}$ \\
\hline
\end{tabular}

Table.4 The comparison of cuttlefish catches with and without FAD during the fishing season

\begin{tabular}{|l|l|l|l|l|}
\hline Cuttlefish fishery & \multicolumn{4}{|c|}{ Mean Catch (Kg/boat/day) \pm SD } \\
\hline Month wise & June & July & August & September \\
\hline With FAD & $567 \pm 0.294$ & $712 \pm 0.22$ & $631 \pm 1.85$ & $580 \pm 1.08$ \\
\hline Without FAD & $308 \pm 0.18$ & $365 \pm 0.34$ & $329 \pm 0.54$ & $272 \pm 0.18$ \\
\hline
\end{tabular}

Fig.1 Location of Kombuthurai fishing village

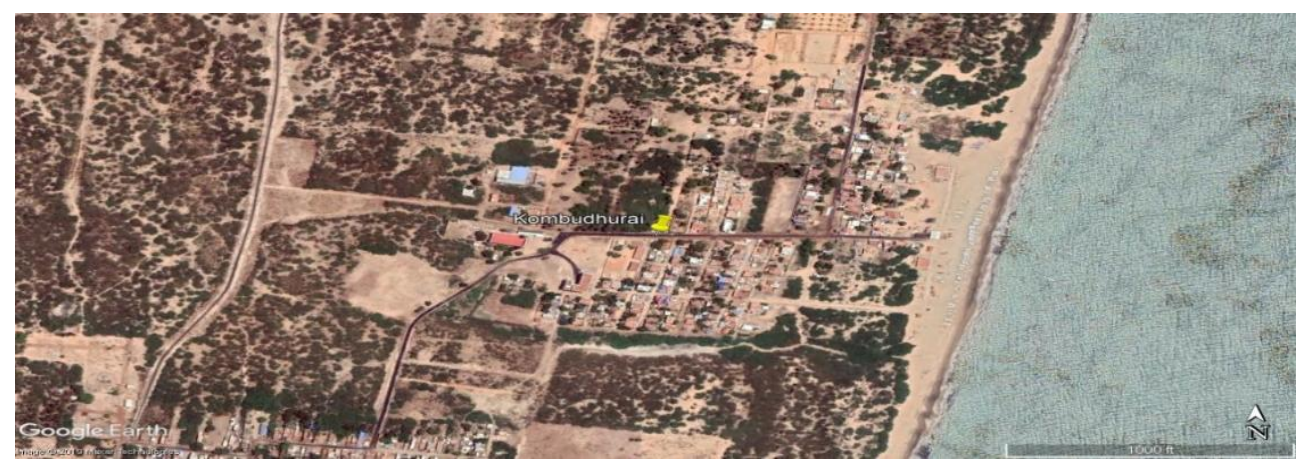


Fig.2 A- Artificial jigs; B- Colourful artificial baits; C- Attractive lights used for catching bait fishes; D- Method of bait fish catching

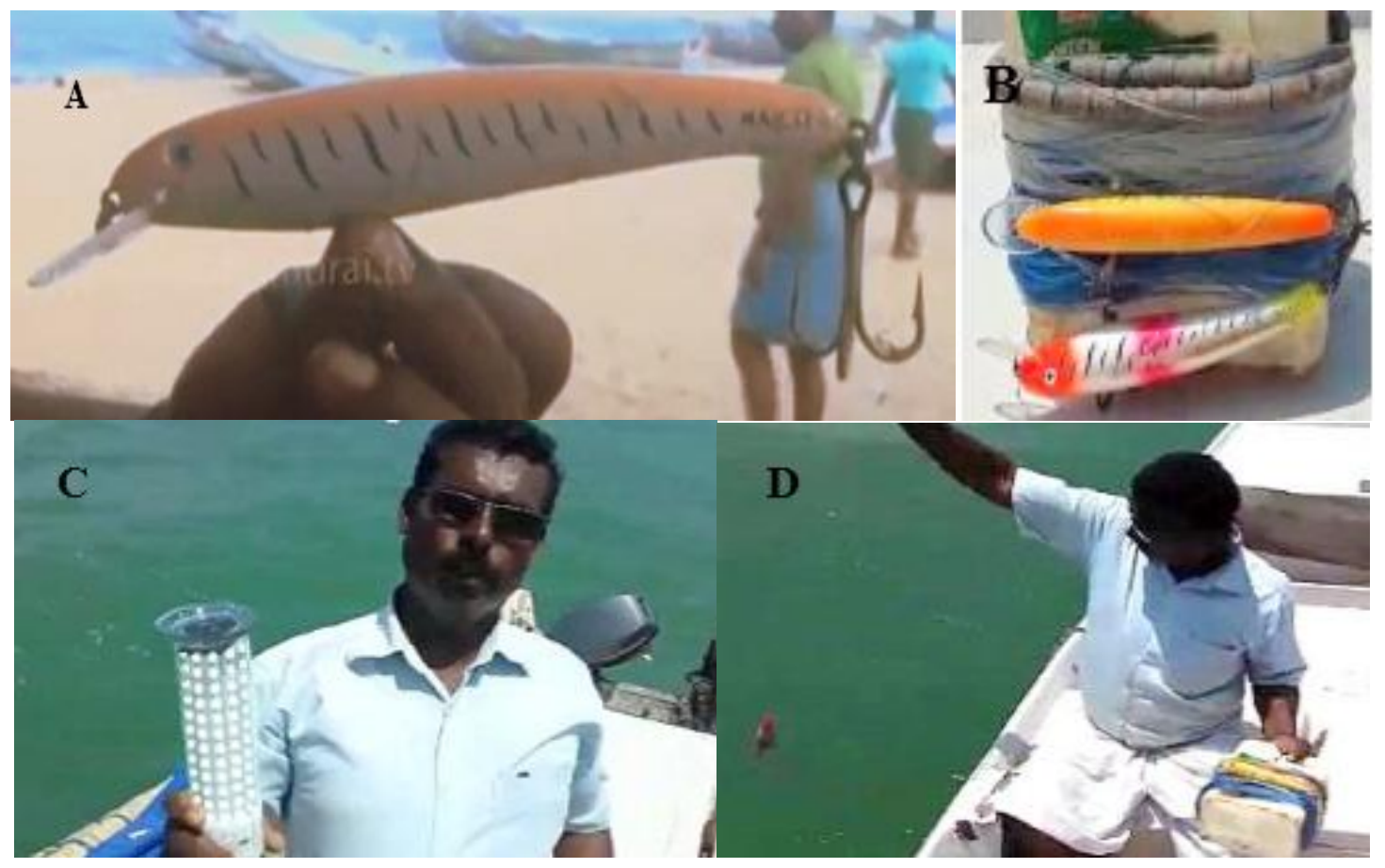

Fig.3 Major targeted species: A- Tuna; B- Seer fish; C- Carangids; D- Cuttlefishes

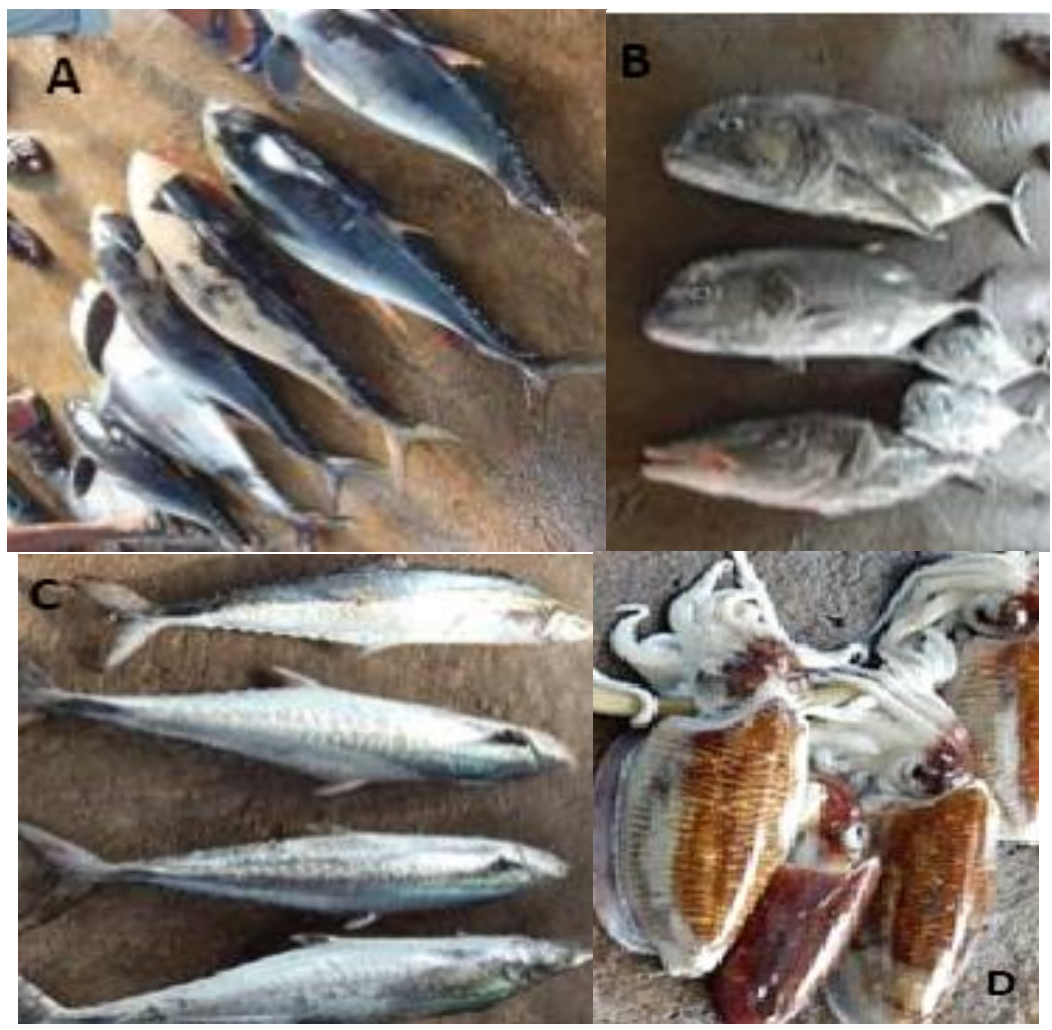


Fig.4 Preparation of Fish Aggregating Devices for cuttlefish fishery: A1 \& A2- Preparing attracting devices using inflorescence; B- Cotton bag filled with sand (Anchoring device); C-

Coconut act as floating device; D \& E- Releasing of FAD into water

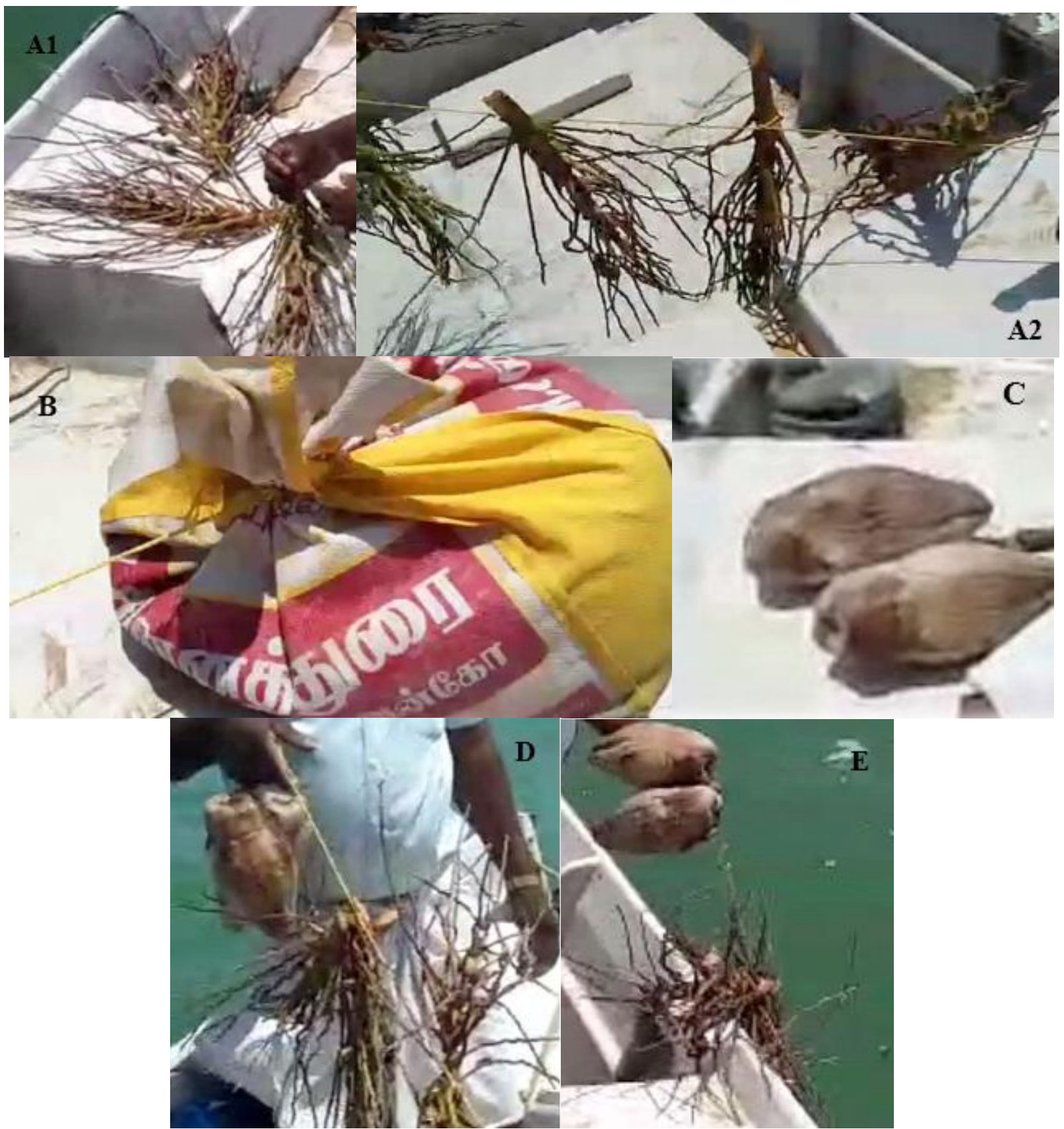

\section{Construction of fish aggregating devices}

A FAD is made up of purely biodegradable materials consists of floating, attracting and anchoring section that installed at small scale level for exploiting cuttle fishes.
Inflorescence of coconut tree was tied in series to make the line that served as attracting devices. About 5-6 kg sand to be filled in a bag and linked to the lower end of the plant line which acts as a sinker. The floating devices are formed using a coconut 
by making a hole and tied on the upper end. The picture for the preparation of FAD is given in Figure 4. Sometimes, the broken piece of a tree also found to be used as the attracting device instead of the inflorescence of a coconut tree.

\section{Cuttlefish fishery}

The cuttlefishes have a reproductive strategy of laying eggs on the suitable substratum. In general, cuttlefishes are occurred in demersal, and they are coming up to pelagic waters for feeding, sheltering and spawning. This strategy was utilized to adopt FAD-associated cuttlefish fishery. There were two major cuttlefish species found in Kombuthurai region namely, Sepia pharaoni and Sepia ramani. Mostly the fishers have gone for fixing FAD at 1.00 am (night time), and then they will come back to shore. 40-50 trees have been fixed per day during the study period.

They used to go for exploiting cuttlefishes at 3.00 am (early morning). During that time, all the cuttlefishes have come towards the FAD for laying eggs. This increases the catching efficiency of cuttlefishes by hand jigging operation and which show a drastic differences in the cuttlefish fishery with and without FAD. The comparison of cuttlefish catches with and without FAD is given in Table 4.

S. pharaoni catch was higher due to their distribution in $32 \mathrm{~km}$ distance $(20 \mathrm{~nm})$ from the shore. The depth of occurrence of $S$. pharaoni was $30-50 \mathrm{~m}$. S. ramani was captured at $100 \mathrm{~km}$ distance from the shore with the depth of $100-120 \mathrm{~m}$. The seasonal abundance of cuttlefishes was reported during the period from June to September in which the catch was found to be maximum in July month with $860 \mathrm{~kg} /$ boat/ day by FADassociated hand jigging.

\section{Marketing channel in Kombuthurai}

The price of fishes which caught by Kombuthurai fishers was found to be higher at around two times than the fishes from other landing centres. All the fishers from Kombuthurai are following unique marketing channels to sell their fishes. Auctioning of catches was done on a daily basis. There were two marketing intermediaries in the marketing channel, such as auctioneer and wholesalers. The auctioneers are involved in auctioning of fishes with $10 \%$ of auction charges which has been collected from fishers through associations. The cost of fishes has been fixed with the help of fishers association based on its size and species. There were four fishers association found in Kombuthurai village, namely, St. Francis Xavier, St. Mudiyappar, Christhu raja, and Sagaya matha. The wholesalers from Thoothukudi, Kanyakumari, Manapad, and Kerala were contributed to the marketing channel of Kombuthurai.

In Indian marine fish production, the mechanised sector was contributed to $83 \%$ whereas the motorised and non-mechanised were contributed to $14 \%$ and $3 \%$ respectively. So, Trawling was found to be the major fishery practices along the Indian coast, which may cause the extreme environmental risk due to the degradation of benthic habitat. The adoption of the ecofriendly fishing method may be an appropriate measure to overcome this issue and to protect the aquatic ecosystem. Hooks and Line fishing is the fuel-efficient and eco-friendly fishing method can be operated even in the rocky and uneven bottom. These are highly size and species selective fishing practices that provide a high quality of fish catches (FAO, 2015). According to Muniyapillai et al., (2015), the hand jigging operation concerned as the best practices for Cuttlefishes by using artificial wooden baits. Long lining is the most sustainable and responsible fishing gear with 
compared to other fishing gears like trawling and gillnetting due to their size and species selection, absence of ghost fishing, survival after the escape, superior fish quality, less energy consumption and small damage to the ecosystem (Bjordal et al., 1996). So, Kombuthurai fishers were concentrated entirely on hook and line based fishing operation without the contribution of other fishing gears. The less fuel consumption due to line fishing operation might have reduced the carbon dioxide emission through fishing activity.

The usage of specific bait fishes based on their preferable feeding habit may increases the catching efficiency drastically. Moreover, the fishermen from Kombuthurai had well knowledge about the ecosystem sustainability, which is the most appreciated thing among the fishers. They are using a hook and line method even to catch bait fishes. The taste, texture, and size of feed influence the feed intake of fishes (Radhakrishnan et al., 2016). The study on marketing channel has shown the price differences of fishes between Kombuthurai and other fish landing centres. This is because of their superior fish quality in Kombuthurai. They have been given a good reason to prove their fish is excellent quality. Fishermen ride the boat at a speed of about $12-16 \mathrm{~km} / \mathrm{hr}$, which will be the same speed of the bait/jig (may be plastic or live bait). So, fish should travel at $20 \mathrm{~km} / \mathrm{hr}$ to capture such a speedy bait. This can be done only by a healthy fish. They are using a small hook for baiting, and they are using a long hook (rod) to kill the freshly caught fishes by a blow on the head. Immediately after catching, the fishes have been kept with ice. So, the quality of fishes is retained for a long period. Likewise, the fishermen have targeted only large sized fishes. This also one of the reasons for good quality and high prices. If they caught small sized fishes, the throwing it back to the sea quickly so that fishes are alive in condition. The aggregation of cuttlefishes in FAD increases the catches. FAD-associated cuttlefish fishery was performed concerning their adaptation and reproductive strategy. All the fishing practices following in Kombuthurai will be retained the fishery stock as a sustainable condition for the future generation.

Kombuthurai fishers, who learnt this traditional knowledge of major fisheries from their ancestors are known to follow this practice for generations since they believe that this method of harvesting resources is a sustainable method. The fishers also feel that their targeted species are available in their sea at the unexploited state. It is also true based on the earlier studies conducted. CPUE of many fisheries is declining worldwide, but all major fishing in Kombuthurai waters remain unexploited.

\section{Acknowledgements}

The authors are grateful to the Kombuthurai fishers, who disclosed their traditional knowledge of their fishing, which is the basis of this study.

\section{References}

Bjordal, A., and Lokkeborg, S., 1996. Long lining, pp.126-140.

Central Marine Fisheries Research Institute Annual Report, 2017-2018.

FAO, 2005. The state of world fisheries and aquaculture. Food and Agriculture Organization of the united nations, Rome, pp. 3-42.

Fernando, H., Ananthan, P.S. and Daniel, N., Shark fishing-A unique traditional fishing practice in Thoothoor, Tamil Nadu, India.

Handbook Thoothukudi. 2011-2012.

Kurien, J. and Achari, T.T.R., 1989. On Ruining the Commons and the 
Commoner the Political Economy of Overfishing, Working paper no. 232, Centre for Development Studies.

Muniyapillai, P., Sundaramoorthy, B., Neethiselvan, N. and Jawahar, P., 2016. Efficiency of handjigging for cuttlefishes in Kombudurai village, southeast coast of Tamilnadu. J. Exp. Zool. India, 19, pp.531-535.

National Fisheries Development Board Report, 2019

Pauly, D., Christensen, V., Guenette, S.,
Pitcher, T.J., Sumaila, R.U., Walters, C.J Watson, R., and Zeller, D., 2002. Towards sustainability in world fisheries, Nature 418: 689-695.

Radhakrishnan, K., Kalaiarasan, M., Madan, M.S., Ananth, P.N., Umamaheswari, T. and Velmurugan, R., 2016. Economic analysis of the hook and line fishery in Kombuthurai Coast, Tamil Nadu. Current World Environment, 11(3), p. 926.

\section{How to cite this article:}

Chellamanimegalai, P., S.J. Abisha Juliet Mary, S. Manickavasagam, G. Kantharajan, M. Dhayanath and Sundaramoorthy, B. 2019. Traditional Fishing Knowledge Followed in Kombuthurai along Gulf of Mannar; A New Approaches on Hand Jigging of Cuttlefishes Using Biodegradable FAD. Int.J.Curr.Microbiol.App.Sci. 8(07): 1703-1711. doi: https://doi.org/10.20546/ijcmas.2019.807.202 